\title{
Social Media Addiction in High School Students: A Cross-Sectional Study Examining Its Relationship with Sleep Quality and Psychological Problems
}

\author{
Adem Sümen $^{1}\left[\right.$ (D) Derya Evgin ${ }^{2}$
}

Accepted: 1 July 2021 /Published online: 3 August 2021

(c) The Author(s), under exclusive licence to Springer Nature B.V. 2021

\begin{abstract}
The aim of this study was to examine the relationship of social media addiction with sleep quality and psychological problems in high school students. The study is a cross-sectional, correlational type. The study was conducted with 1,274 students receiving education in a district located in the western region of Turkey. For the collection of the data, a Descriptive Information Form, the Social Media Addiction Scale for Adolescents (SMASA), the Strengths and Difficulties Questionnaire (SDQ), the Sleep Quality Scale (SQS) and the Sleep Variables Questionnaire (SVQ) were used. Among the high school students who participated in the research, $49.3 \%$ stated that they had been using social media for $1-3$ years, $53.9 \%$ reported that they spent $1-3 \mathrm{~h}$ per day on social media, and $42.8 \%$ stated that they placed their telephone under their pillow or beside their bed while sleeping. Students' mean scores were $16.59 \pm 6.79$ (range: 9-45) for the SMASA, 16.54 \pm 4.27 (range: 0-40) for total difficulties, and 14.18 \pm 1.56 (range: 7-21) for the SQS, while their sleep efficiency value was $97.9 \%$. According to the research model, difficulties experienced by high school students increase their social media addiction, while they decrease prosocial behaviours. Social media addiction in high school students decreases students' sleep efficiency $(\mathrm{p}<0.05)$. It is considered important to conduct further public health studies for children and adolescents related to the risks caused by the excessive use of technology, the consequences of social media addiction, measures to protect psychological health, sleep programmes and the importance of sleep quality.
\end{abstract}

Keywords Adolescent $\cdot$ Difficulties $\cdot$ Nursing $\cdot$ High school student $\cdot$ Social media addiction $\cdot$ Sleep quality

Adem Sümen

ademsumen@akdeniz.edu.tr

Extended author information available on the last page of the article 


\section{Introduction}

Together with the very rapid digitalization in our age, the use of social media is increasing in our country and in the world (Ersöz \& Kahraman, 2020; Singh et al., 2020). According to the Digital 2021: Global Overview Report, the time spent on social media has increased 1.5 times in the last 5 years. The most widely used social networks are listed as: Facebook, YouTube, WhatsApp, FB Messenger, Instagram, WeChat, TikTok and QQ (DataReportal, 2021a). As for Turkey, the use of social media has increased by $11.1 \%$ in the past year, and YouTube, Instagram, WhatsApp, Facebook, Twitter and FB Messenger are the most frequently used social networks (DataReportal, 2021b). When the way of dealing with social media addiction is examined, it can be said that nowadays, social media addiction has ceased to be an ordinary problem and become a disease associated with a global epidemic. People all over the world can show excessive interest in social media and spend a great deal of time using social media. For this reason, social media has a negative effect on the lives of millions of people in the world (Andreassen, 2015; Singh et al., 2020).

In a study by Drahošová and Balco (2017), in which they investigated the advantages and disadvantages of social media use, $97.7 \%$ of participants stated that the advantages of using social media were communication and the exchange of information, while $72.2 \%$ stated that the biggest disadvantage was internet addiction. It is known that among users, especially the younger age group faces the risk of addiction. Although social media is regarded as a new area of socialization and that this situation is an advantage (Savc1 \& Aysan, 2017), it is also reported that social media has a negative effect on interpersonal relationships (Çalışır, 2015), psychological health (Chen et al., 2020) and private life (Acılar \& Mersin, 2015), increases levels of depression (Haand \& Shuwang, 2020), and leads to social media addiction. Indeed, it has been determined that in the case of adolescent users, excessive levels of use are associated with paranoid thoughts, phobic anxiety and feelings of anger and hostility (Bilgin, 2018). Moreover, an increase in periods of social media use can cause a reduction in sleep quality (Eroğlu \& Y1ldırım, 2017). Poor sleep quality can lead to daytime sleepiness in students and to negative effects on their performance, school achievement, activities and energy (Güneş et al., 2018).

Due to the coronavirus pandemic, the switch to the distance education process was made in line with the restrictions implemented for protecting public health. The extension of periods spent at home by adolescents has led to long periods of exposure to screens, a restriction of outdoor activities, a reduction in peer interactions, unhealthy sleep patterns, and increases in stress and anxiety levels (Liu et al., 2021; Wang et al., 2020). Based on this, the aim of this study is to examine the relationship of social media addiction with sleep quality and psychological problems in high school students. 


\section{Method}

\subsection{Study Design}

This is a cross-sectional, correlational type of research. In this study, which was conducted in order to determine the relationship of social media addiction with sleep quality and psychological problems in high school students, a path analysis study was made in line with the examined literature and the aim, and the theoretical model is shown in Fig. 1. The model consists of four hypotheses, and the correlations between the variables in these hypotheses are included in the model.

$\mathrm{H}_{1}$ : Difficulties experienced by high school students (emotional problems, conduct problems, attention deficit and hyperactivity, and peer problems) increase social media addiction.

$\mathrm{H}_{2}$ : Prosocial behaviours in high school students decrease social media addiction.

$\mathrm{H}_{3}$ : Social media addiction in high school students increases poor sleep quality.

$\mathrm{H}_{4}$ : Social media addiction in high school students decreases sleep efficiency.

\subsection{Participants}

The study was conducted in 15 high schools affiliated to a District National Education Directorate in the south of Turkey. A total of 4,602 students are registered at these high schools in the 2020-2021 academic year. Since education at the schools is carried out in the form of distance education within the scope of the COVID-19 measures, the research was carried out online via the District National Education Directorate and the school principals. The study was completed between 01-30 December 2020 with a total of 1,274 people with the aim of reaching all students. Students registered at high school and volunteering to participate in the study were included in the research. A $99 \%$ error rate and $3.07 \%$ confidence interval originating from the sample number of the research were found.

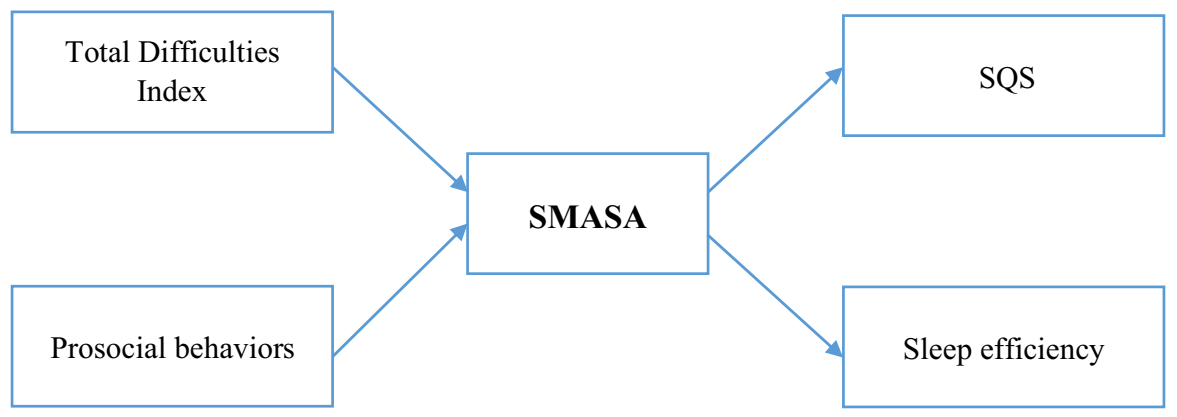

Fig. 1 Path diagram of the research model. SMASA: Social Media Addiction Scale for Adolescents, SQS: Sleep Quality Scale 


\subsection{Data Collection Tools}

A Descriptive Information Form prepared by the researchers by examining the literature, the Social Media Addiction Scale for Adolescents, the Strengths and Difficulties Questionnaire, the Sleep Quality Scale, and the Sleep Variables Questionnaire were used for data collection.

Descriptive Information Form This was prepared in line with the literature, and consists of questions related to adolescents' socio-demographic characteristics, school achievement, family, friend relationships, sleep status, and extent of using social media. School achievement and relationship levels were classified as "good", "average" or "poor" depending on the students' own statements.

Social Media Addiction Scale for Adolescents (SMASA) This scale was developed by Özgenel et al. (2019) with the aim of determining adolescents' levels of social media addiction. The scale consists of a single factor and includes nine items. The highest score that can be obtained from the five-point Likert-type scale is 45 , while the lowest score is 9. It can be said that adolescents' social media addiction is greater as scores obtained in the scale increase, while as scores decrease, their level of addiction is lower. The Cronbach alpha internal consistency reliability coefficient of the scale is 0.904 . In this study, however, the Cronbach alpha value was found to be 0.880 .

Strengths and Difficulties Questionnaire (SDQ) Developed by Goodman (1997), this scale is extensively used all over the world to examine children's and adolescents' psychological and behavioural problems. The scale was adapted to Turkish by Güvenir et al. (2008). Consisting of a total of 25 questions, the scale is scored with a three-point Likert-type rating, and the questions are scored as " 0 ", " 1 " and "2" according to their degree of accuracy. The scale includes subscales of emotional problems, conduct problems, attention deficit and hyperactivity, peer problems, and prosocial behaviours, each containing five questions. Although each subscale can be evaluated in itself, the total of the first four subscales gives a total difficulty score. While high scores for prosocial behaviours reflect an individual's strengths in the social domain, high scores in the other four domains indicate that the problem areas are severe. The Cronbach alpha internal consistency reliability coefficient of the scale is 0.73 , while in this study, the Cronbach alpha value was found to be 0.776 .

Sleep Quality Scale and Sleep Variables Questionnaire (SQS-SVQ) This scale was developed by Meijer and van den Wittenboer (2004), and the Turkish validity and reliability study was carried out by Önder et al. (2016). Seven scale items that measure sleep quality and eight questionnaire items that identify parental control, total sleep time, midpoint of sleep, and sleep efficiency are included in the SQS-SVQ. Each of the SQS items have three categories scored from 1 to 3. Scores that can be obtained from the scale range between 7 and 21. A high score obtained from the scale indicates poor sleep quality, while a low score indicates good sleep quality. 
Among the SVQ items, however, only sleep efficiency was calculated and used. The Cronbach alpha internal consistency reliability coefficient of the scale is 0.72 . In this study, however, the Cronbach alpha value was calculated as 0.714.

\subsection{Data Collection}

The data were collected by using an online web-based questionnaire via Google Forms. The questionnaire was sent to the students through social media networks via the District National Education Directorate and the school principals. Before beginning the study, the study aim and method were explained to the students and their families, and it was stated that the data would be used only for scientific purposes, that the data would be kept confidential, that the study would be conducted based on the principle of voluntariness, and that participants were free to take part in the research or not. After the students who agreed to take part in the study had confirmed that they were volunteers in an electronic environment, they began to reply to the questions. It took an average of 15-20 min to respond to the questionnaires. A total of 1,366 students filled in the form. When the forms were examined after the study, 92 forms were not evaluated due to missing data. Therefore, the data collection process was completed with 1,274 students.

\subsection{Data Evaluation}

The statistical analyses of the data were made using the SPSS Statistics Base V 23 version of Statistical Package for the Social Sciences and AMOS 21.0 software. For evaluating the data of the study, descriptive statistical methods (frequency, percentage, mean and standard deviation) were used; to test the differences between groups, t-test for independent variables and one-way variance analysis were performed; for comparisons between groups, the post-hoc Bonferroni and Tukey tests for multiple comparisons were utilised. In the research, the path analysis method was applied to test the hypotheses of the model created to determine the relationship of social media addiction with psychological problems and sleep quality. The results were evaluated at a 95\% confidence interval and at $\mathrm{p}<0.05, \mathrm{p}<0.01$ and $\mathrm{p}<0.001$ significance levels.

\subsection{Ethical Aspect of the Research}

To be able to conduct the research, institutional permission was obtained from Antalya Provincial Directorate of Education (date: 25/09.2020, No: E.13536854), while ethical approval was obtained from Akdeniz University Clinical Research Ethics Committee (date: 19/02/2020, No: KAEK-174). Meetings were held with school principals of all the schools, and the research aim, content and method were explained to them. Participants' consent was obtained by making an announcement about the study on the first page of the online link of the data collection tools. 


\section{Results}

Among the high school students participating in the research, $70.0 \%$ were girls, and their average age was $15.36 \pm 1.22$. Approximately half of the students were studying in first grade (45.4\%), while over half of them $(61.9 \%)$ stated that their school achievement level was average. The majority of students reported that they had good relationships with their mothers $(85.2 \%)$, fathers $(77.1 \%)$, siblings (72.2\%) and friends $(77.5 \%)$. It was revealed that $75.1 \%$ of students decided when to go to bed themselves, $65.6 \%$ did not turn off their telephones while sleeping, $44.6 \%$ kept their telephones away from the bed, and $42.8 \%$ placed their telephones under their pillow or beside their bed. The majority of students stated that they had been using social media for 1-3 years (49.3\%), and that they spent $1-3 \mathrm{~h}$ per day on social media (53.9\%), while $35.9 \%$ checked their social media as soon as a notification came. $10.3 \%$ of students considered themselves to be social media addicts, while $72.7 \%$ believed that society was addicted to social media (Table 1 ).

The high school students' mean SMASA score was determined to be $16.59 \pm 6.79$. For the SDQ, their mean score for total difficulties was calculated as $16.54 \pm 4.27$. Among the SDQ subscales, the highest mean score was for prosocial behaviours with $7.94 \pm 1.88$, while the lowest was for conduct problems with $2.23 \pm 1.49$. The total SQS mean score was calculated as $14.18 \pm 1.56$, while the sleep efficiency value was calculated as $97.9 \%$ (Fig. 2).

Mean SMASA scores of female students $(\mathrm{p}<0.001)$, students with poor school achievement $(\mathrm{p}<0.001)$, students who had poor relationships with their mothers $(\mathrm{p}<0.001)$, fathers $(\mathrm{p}<0.001)$, siblings $(\mathrm{p}<0.001)$ and friends $(\mathrm{p}<0.05)$, whose parents decided on their bedtime $(\mathrm{p}<0.05)$, who did not turn off their telephones while sleeping $(\mathrm{p}<0.001)$, who had been using social media for more than seven years $(\mathrm{p}<0.001)$, who spent more than seven hours on social media per day $(\mathrm{p}<0.001)$, who checked their social media notifications at every spare moment $(\mathrm{p}<0.001)$, and who considered themselves $(\mathrm{p}<0.001)$ and society $(\mathrm{p}<0.001)$ to be social media addicts were found to be higher. Female students $(\mathrm{p}<0.05)$, students who had poor relationships with their mothers $(\mathrm{p}<0.01)$ and siblings $(\mathrm{p}<0.05)$, and those who did not turn off their telephones while sleeping $(p<0.01)$ were determined to have higher mean SQS scores. It was revealed that female students $(\mathrm{p}<0.001)$, students with poor school achievement $(\mathrm{p}<0.001)$, students who had poor relationships with their mothers $(\mathrm{p}<0.001)$, fathers $(\mathrm{p}<0.001)$, siblings $(\mathrm{p}<0.001)$ and friends $(\mathrm{p}<0.001)$, who had used social media for more than seven years $(\mathrm{p}<0.005)$, who spent more than seven hours on social media per day $(\mathrm{p}<0.001)$, who checked their social media notifications at every spare moment $(\mathrm{p}<0.001)$, and who considered themselves $(\mathrm{p}<0.001)$ and society $(\mathrm{p}<0.001)$ to be social media addicts had higher mean SDQ scores (Table 1).

In the study, a positive correlation of students' mean SMASA scores with SDQ-conduct problems, SDQ-attention deficit, SDQ-emotional problems, SDQpeer problems, SDQ-total difficulties index and total SQS mean scores was found, while a negative correlation was found with SDQ-prosocial behaviours and SVQsleep efficiency mean scores $(\mathrm{p}<0.01)$ (Table 2$)$. 


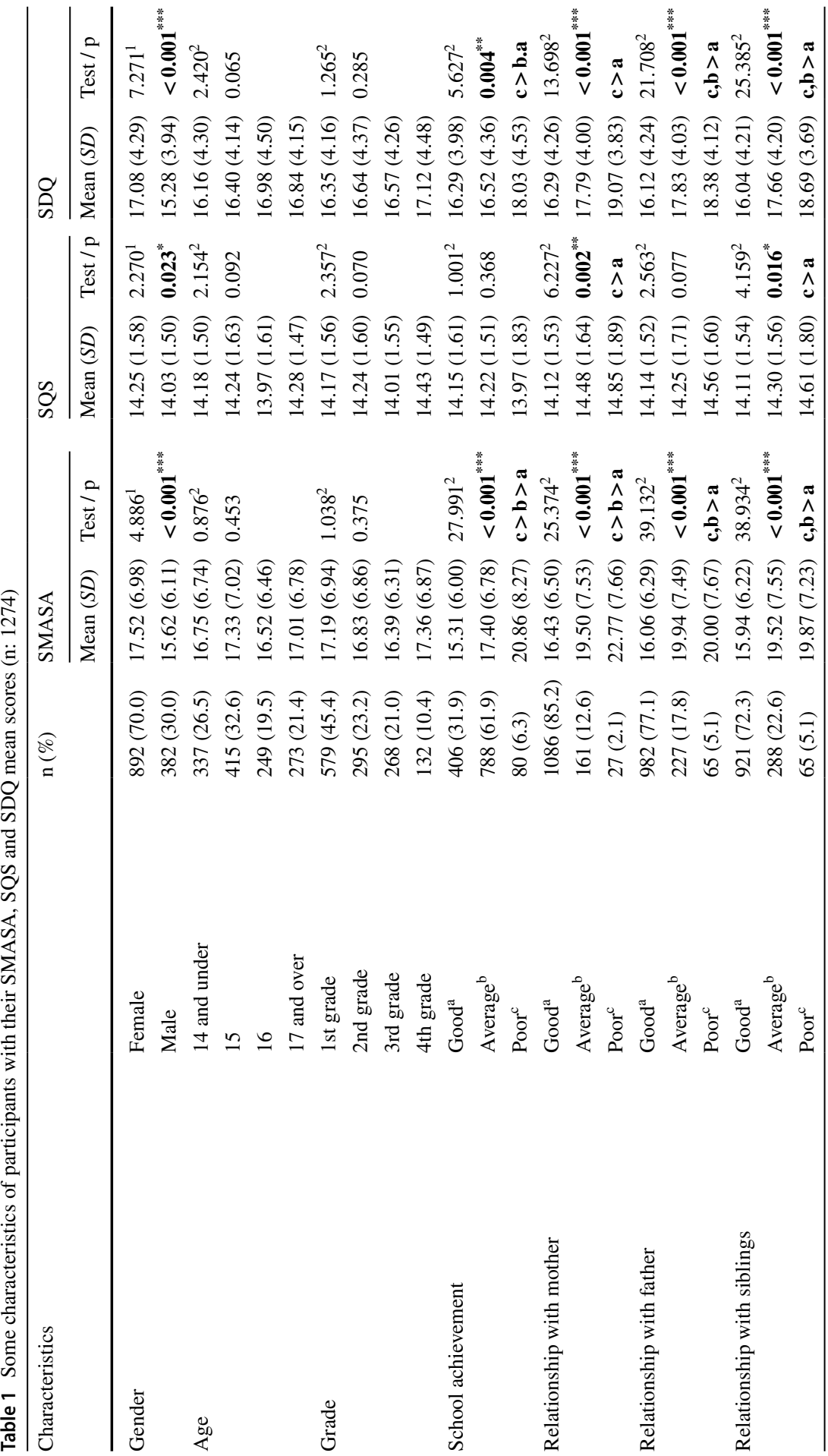




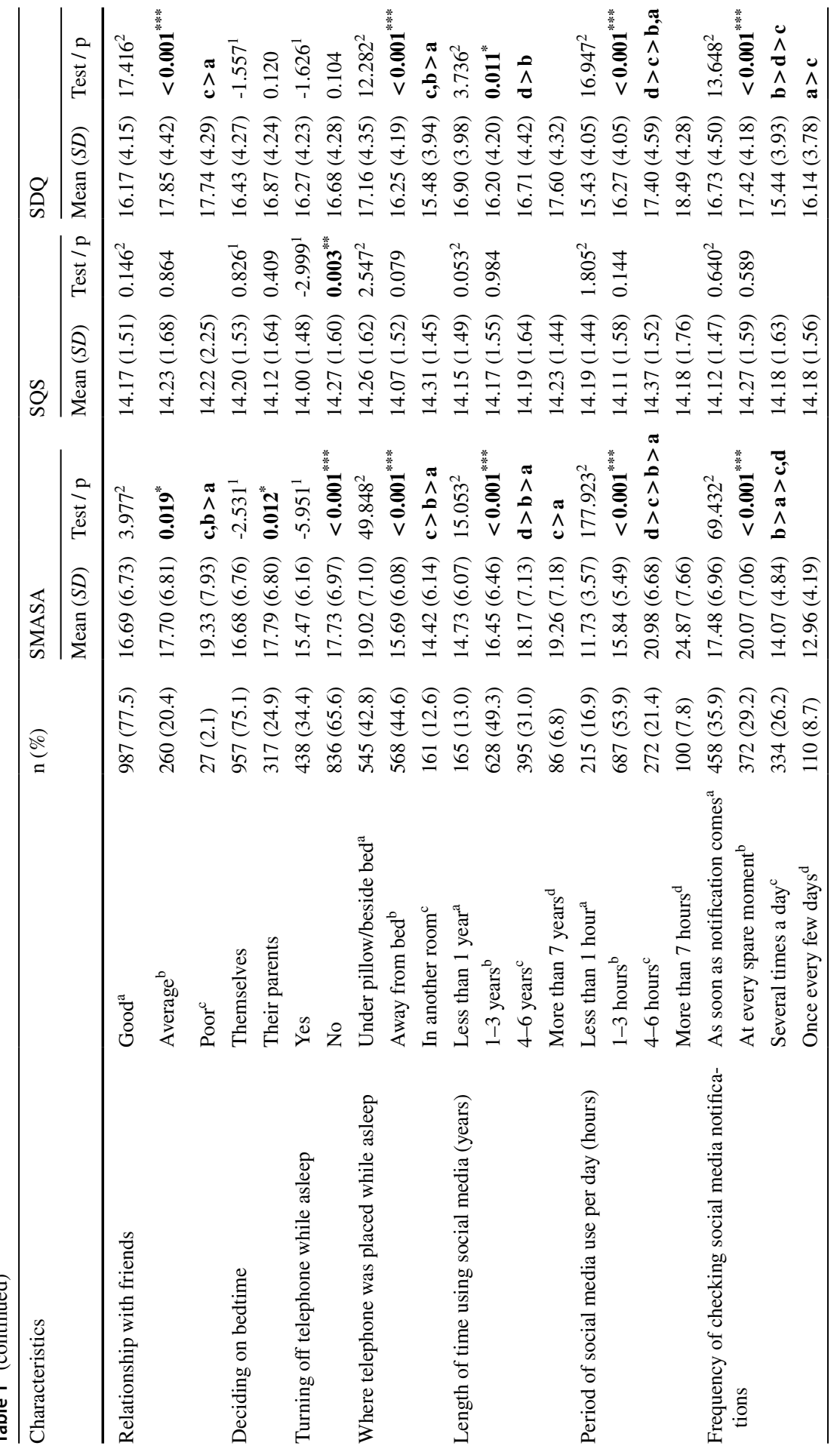




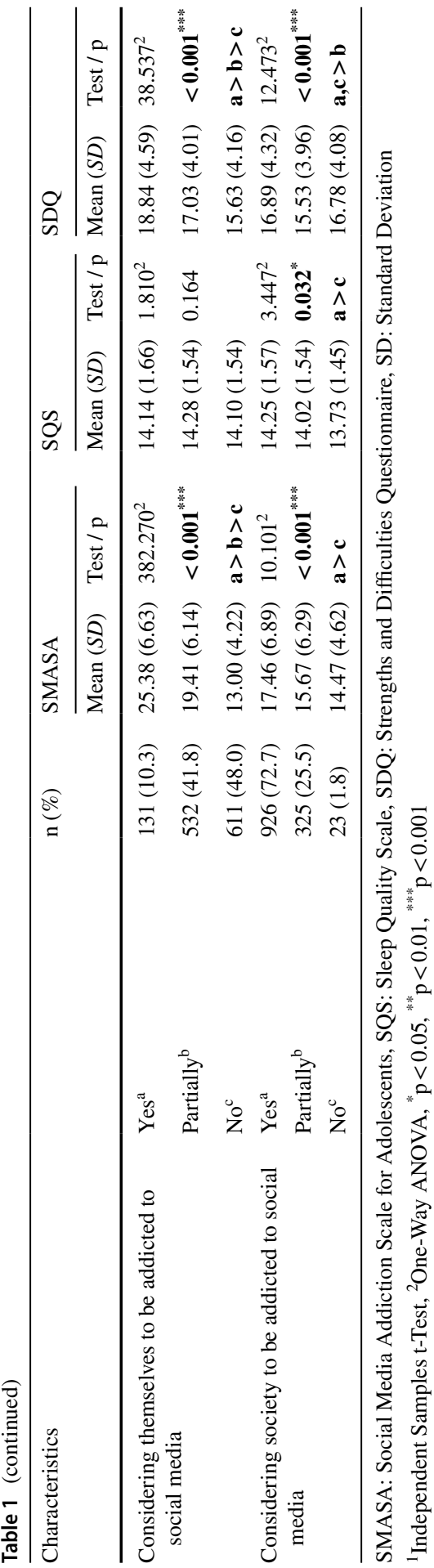




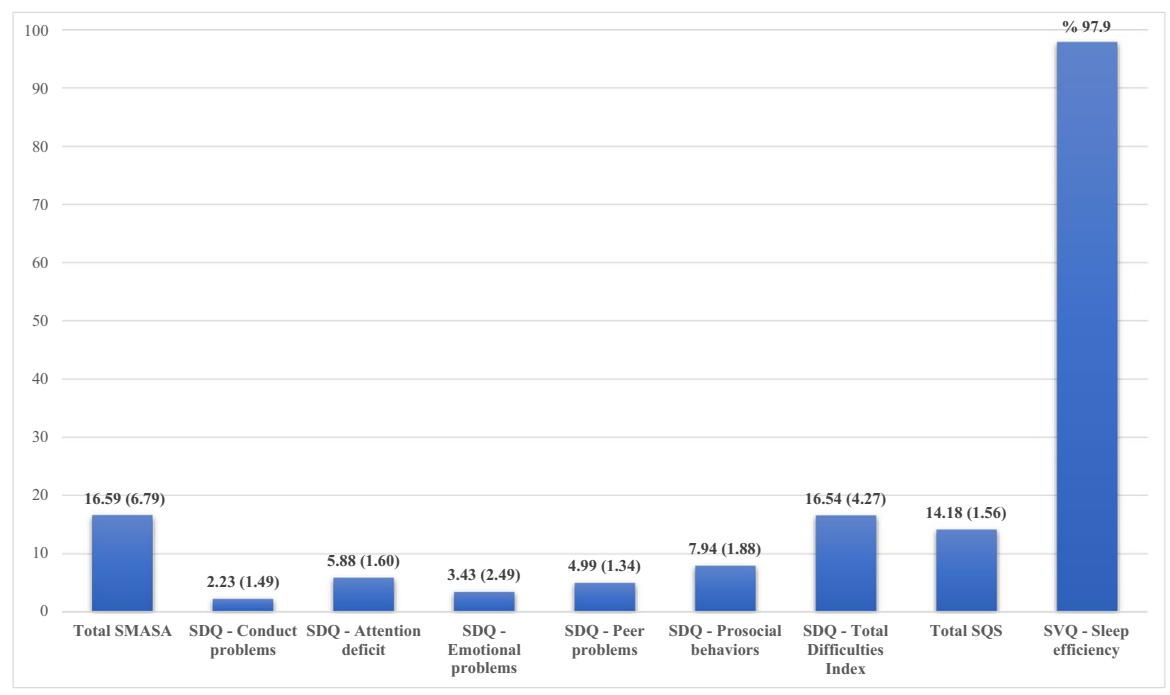

Fig. 2 Participants' SMASA, SQS-SVQ and SDQ total and subscale mean scores (n: 1274)

Table 2 Correlation between SMASA, SQS-SVQ and SDQ Mean Scores (n: 1274)

\begin{tabular}{lcc}
\hline Scale & \multicolumn{2}{l}{ Total SMASA } \\
\cline { 2 - 3 } & $\mathrm{r}$ & $\mathrm{p}$ \\
\hline SDQ_Conduct problems & 0.296 & $<0.001^{* *}$ \\
SDQ-Attention deficit & 0.111 & $0.001^{*}$ \\
SDQ-Emotional problems & 0.345 & $<0.001^{* *}$ \\
SDQ_Peer problems & 0.182 & $<0.001^{* *}$ \\
SDQ-Prosocial behaviours & -0.273 & $<0.001^{* *}$ \\
SDQ-Total difficulties index & 0.400 & $<0.001^{* *}$ \\
Total SQS & 0.133 & $<0.001^{* *}$ \\
SVQ-Sleep efficiency & -0.194 & $<0.001^{* *}$ \\
\hline
\end{tabular}

SMASA: Social Media Addiction Scale for Adolescents, SQS: Sleep Quality Scale, SDQ: Strengths and Difficulties Questionnaire, SVQ: Sleep Variables Questionnaire

r: Pearson correlation coefficient, ${ }^{*} \mathrm{p}<0.01,{ }^{* *} \mathrm{p}<0.001$

The standardised estimates related to the research model drawn within the scope of the study are given in Table 3. According to the research model, difficulties experienced by high school students have a positive effect on social media addiction $(\beta=0.293)$, while prosocial behaviours have a negative effect on social media addiction $(\beta=-0.159)(\mathrm{p}<0.05)$. Social media addiction in high school students has a negative effect on sleep efficiency $(\beta=-0.094, p<0.05)$. As a result of the path analysis, it was determined that the goodness-of-fit indices of the model had acceptable values and that model-data fit was achieved (İlhan \& Çetin, 2014; 
Table 3 Results related to research model (n: 1274)

\begin{tabular}{llllll}
\hline Effect & Estimate $(\beta)$ & Standard Error & $\mathrm{t}$ & $\mathrm{p}$ & Result \\
\hline Total Difficulties Index SMASA & 0.293 & 0.042 & 11.080 & $* * *$ & $\mathrm{H}_{1}$ accepted \\
Prosocial behaviours SMASA & -0.159 & 0.095 & -6.016 & $* * *$ & $\mathrm{H}_{2}$ accepted \\
SMASA SQS & 0.033 & 0.006 & 1.170 & 0.242 & $\mathrm{H}_{3}$ rejected \\
SMASA Sleep efficiency & -0.094 & 0.029 & -3.364 & $* * *$ & $\mathrm{H}_{4}$ accepted
\end{tabular}

Fit Indices

$\chi$ 2/df: 2.872, RMSEA: 0.038, GFI: 0.994, AGFI:0.986, CFI: 0.936, SRMR: 0.011

SMASA: Social Media Addiction Scale for Adolescents, SQS: Sleep Quality Scale, *p $<0.05$

Kline, 2011). Accordingly, hypotheses $\mathrm{H}_{1}, \mathrm{H}_{2}$ ve $\mathrm{H}_{4}$ relating to the model were accepted, while hypothesis $\mathrm{H}_{3}$ was not accepted (Table 3).

\section{Discussion}

Social media use by individuals has steadily increased in recent years (Dong et al., 2020; Fernandes et al., 2020; Kashif \& Aziz-Ur-Rehman, 2020; Lemenager et al., 2021). Especially young people increasingly use social media and the internet, which is an easily and rapidly accessible means of mass communication, frequently for academic and other purposes. These tools are not merely a source of information, their use is also sought for other purposes such as social interaction, games and entertainment (Singh \& Barmola, 2015). The decrease seen in individuals' interaction in social life and the increase in the time they spend at home due to the COVID-19 pandemic have increased the use of online communication tools (Benke et al., 2020; King et al., 2020; Oliviero et al., 2021). The steady increase in internet and social media addiction among young people in recent years has already been reported (Fernandes et al., 2020; Kashif \& Aziz-Ur-Rehman, 2020; Orben et al., 2020; Scott et al., 2019). However, in this study, it was seen that high school students' mean social media addiction scores $(16.59 \pm 6.79)$ were below average.

In the Addiction Prevention Training Programme of Turkey implemented by Green Crescent (2017), certain criteria were defined concerning the case of whether or not high school students' are addicted to social media. Accordingly, it is stated that if social media is the first choice that comes to mind in cases of boredom, if it takes precedence over real life, if it leads to disruption of daily life and negligence of responsibilities, if it takes up an excessive amount of time and creates anxiety when it cannot be accessed, if the need is felt to constantly share things, then adolescents may be addicted to social media. The majority of students included in the scope of the study stated that they had been using social media for 1-3 years (49.3\%), and that they spent $1-3 \mathrm{~h}$ on social media per day (53.9\%), while $35.9 \%$ checked their social media whenever a notification came. Therefore, it can be said that students taking part in the study were at risk of social media use disorder. However, another important finding of the study is that while one in ten students regarded themselves as social media addicts, around three-quarters of them considered that society was 
addicted to social media. This situation in fact shows that the students had awareness regarding social media addiction, but that they did not accept addiction for themselves. In a study conducted by Fernandes et al. (2020) on adolescents in India, Malaysia, Mexico and Great Britain, it was found that during the pandemic, periods of social media use, playing online games, and watching video content increased significantly compared to before the pandemic. In other conducted studies, it is also seen that the period spent on social media has increased during the pandemic compared to before the pandemic (71.4\%) (Lemenager et al., 2021), and that people frequently spend their free time on social media during the pandemic $(67 \%)$ (Kashif \& Aziz-Ur-Rehman, 2020).

In the study, it was revealed that social media addiction scores were higher in students who had poor relationships with their mothers, fathers, siblings and friends. Social media prevents adolescents from forming close personal relationships with their families and immediate environment. Social media use disorder also causes weak family and friend relationships in adolescents (Moreno \& Uhls, 2019). Numerous problems emerge due to the misuse of social media. In the study, it was determined that mean SQS scores were higher in students who had poor relationships with their mothers and siblings, and those who did not switch off their telephones while sleeping. It has been found that adolescents with high levels of problematic internet use and of social media use suffer from depression, loneliness, lower sleep quality and high anxiety levels (Bányai et al., 2017; Alonzo et al., 2020; Fernandes et al., 2020; Orben et al., 2020). In some studies, a statistically significant correlation between social media use and adolescent sleep patterns, especially delayed sleep onset, has been determined (Alimoradi et al., 2019; Gradisar et al., 2013; Scott et al., 2019). In the study, students' total sleep quality mean score $(14.18 \pm 1.56)$ was revealed to be poor, and their sleep efficiency value was calculated as $97.9 \%$. This shows that the adolescents included in the sample were unable to sleep efficiently and that their sleep quality was low. This situation may be the result of changes in sleep habits of adolescents due to remaining at home because of the coronavirus pandemic. Similarly, in a study carried out in Italy, it was determined that as a result of the isolation measures taken against the coronavirus, a big delay in children' sleeping/waking schedules and an increase in sleep disorders occurred in all age groups (Oliviero et al., 2021). In another study, it was revealed that problems occurred in adolescents during the pandemic, such as delay in falling asleep, reduction in length of sleep, respiratory impairment during sleep, and sleepiness during the day, and that sleep routines were disrupted (Becker \& Gregory, 2020). The problem of lack of sleep is very common in adolescents, and is an important public health problem that needs intervention in several aspects, such as mental health, obesity and academic performance (Owens, 2014; Sampasa-Kanyinga et al., 2020).

In the study, the high school students' mean total difficulties score in the SDQ was calculated as medium level $(16.54 \pm 4.27)$. Among the SDQ subscales, the highest mean score was found to be for prosocial behaviours, while the lowest was for conduct problems. The high level of prosocial behaviours and low level of conduct problems in the sample group indicates that the research group were able to cope with difficulties. A negative correlation was found between SDQ-prosocial behaviours and SVQ-sleep efficiency mean scores in the study. This situation can be 
interpreted to say that social media use can lead to lack of sleep in students, and that students' prosocial behaviours can decrease. Pandemic adolescents showed higher levels of other problems and a more problematic social media usage than peers before the pandemic (Muzi et al., 2021). Moreover, significant increases are seen in individuals' rates of problematic internet use and of social media use due to the pandemic, and it is stated that this situation creates negative effects in terms of individuals' psychological health (Baltacı et al., 2021; Oliviero et al., 2021). In a qualitative study conducted by Baltaci et al., (2020), it was stated that students experienced difficulties in controlling their internet use during the pandemic, and that since they were unable to control this, they experienced negative emotions and regarded themselves as internet addicts due to this situation.

Evidence suggests that problematic use of gaming, the internet, and social media among adolescents is on the rise, affecting multiple psycho-emotional domains. Moreover, excessive use of digital activities and smartphones may result in multiple mental and physical problems, such as behavioural addiction, cognitive impairment, and emotional distress (Ophir et al., 2020). It was found that as students' mean social media scores increased, their mean scores for attention deficit, conduct problems, emotional problems, peer problems and total difficulties index also increased. In addition, it has been determined that the difficulties experienced by high school students (emotional problems, conduct problems, attention deficit and hyperactivity, and peer problems) increase social media addiction $\left(\mathrm{H}_{1}\right)$. It is emphasized that spending a long time on the Internet increases the possibility of exposure to risks and pathological tendencies, and that the time spent using social media is harmful to mental health (Alonzo et al., 2020; Coyne et al., 2020; Stockdale \& Coyne, 2020; Twigg et al., 2020). It is known that during the pandemic, missing the daily routines that school brings and absence of time spent with peers causes adolescents to experience a great number of problems. These problems can be listed as increase in monotonous time spent at home, disrupted sleep habits, increased exposure to screens, intensive internet use, increased eating habits, decreased physical activity, increased attention and concentration problems, loss of academic achievement due to reduced motivation, increased domestic conflicts, inability to cope with negative emotions such as aggression, boredom, anger and anxiety, increased emotional activity, and deterioration of emotion regulation skills (Ghosh et al., 2020; Lee, 2020; Oliviero et al., 2021). In support of the literature, in this study, too, it was seen that especially during these difficult times that we have been going through, the high school students' social relationships were weakened, their school achievement decreased, the frequency and length of their social media use increased, and there was an increase in the psychological problems and social media addiction that they experienced. This situation reveals that adolescents are at risk biopsychosocially in terms of healthy development and acquiring identity, and with regard to other risks (cyber violence, obesity, loneliness, depression, anxiety, etc.) that the digital environment will bring (Orben et al., 2020). Especially the greater amount of time that adolescents spend using social media has increased the negative effects on adolescents' general health and wellbeing, including sleep (Dong et al., 2020).

Another important result of the study is the finding that prosocial behaviors reduce social media addiction in high school students $\left(\mathrm{H}_{2}\right)$. Some studies showed 
that there were short comings in social skills associated with social interactions and internet and social media addiction (Chua et al., 2020; Dalvi-Esfahani et al., 2021). While the effective use of the internet creates an opportunity for the adolescent, its excessive use may negatively affect the adolescent's physical, psychological, social and cognitive development (Hou et al., 2019). A study found that depression, bullying, loneliness, and sleep quality are among the most common health problems that arise from social media use (Royal Society for Public Health, 2020). Kurulan araştırma modelinde, sosyal medya bağımlılığının lise öğrencilerinde kötü uyku kalitesini etkilemediği $\left(\mathrm{H}_{3}\right)$ fakat uyku verimliliğini $\left(\mathrm{H}_{4}\right)$ azalttığı sonucuna varılmıştır. There are studies showing that social media addiction is positively associated with poor sleep quality (Alfaya et al., 2021; Ho, 2021; Tandon et al., 2020; Wong et al., 2020). According to Garett et al. (2018), using social media for longer periods of time and spending more time with social media causes the quality of sleep of users to decrease. Wong et al. (2020) determined that both the severity of internet gaming disorder and social media addiction were positively related to psychological distress and sleep disorder. In a study on social media use, sleep quality, and well-being in 467 adolescents, it was found that social media use was associated with poor sleep, anxiety, depression, and low self-esteem. Poor sleep was most strongly associated with nighttime social media use (Woods \& Scott, 2016). It is important for the development of a healthy generation to educate adolescents about conscious social media and smart phone use and to emphasize the importance of sleep habits (Gica, 2020).

\section{Conclusions}

According to the results obtained in the study, the students' scores for social media addiction and psychological problems were found to be below average, while their sleep quality scores were negatively above. Although it is known that sleep is very important for adolescent health, it was determined that increased social media addiction in the students in the sample group increased the potential for the emergence of health and sleep problems. It should be borne in mind that the social distancing, recommendations to stay at home, and distance education implemented due to the pandemic can lead to greater flexibility in sleeping and waking times, and can cause an increase in the use of technology for long periods and in social media addiction. It was seen that social media addiction in students was positively correlated with conduct and emotional problems, attention deficit/hyperactivity, peer problems and poor sleep quality, and negatively correlated with prosocial behaviours and sleep efficiency. Based on this, school health nurses should plan and implement appropriate intervention methods in collaboration with other healthcare personnel (psychologists, school counsellors, social workers, etc.). Enabling high school students' access to the correct information sources, open and transparent sharing of information, planning daily routines at home such as meals, sleep and homework, increasing physical activities, expanding intelligent internet use that will support personal and social development, enabling adolescents' return to the peer and school environment by creating safe school environments in as short a time as possible, creating 
alternative means and support groups for peer interaction by reducing isolation and loneliness, and appropriate therapeutic interventions such as sleep education and interventions can be listed among these measures and precautions.

Acknowledgements The authors are grateful to all the high school students for their cooperation in this study.

Author Contribution Adem Sümen: Conceptualization, Methodology, Software, Formal analysis, Data curation, Writing-Original draft preparation.

Derya Evgin: Methodology, Software, Resources, Data curation, Supervision, Validation.

Funding This research did not receive any specific grant from funding agencies in the public, commercial, or not-for-profit sectors.

Data Availability The data that support the fndings of this study are available from the corresponding author upon reasonable request.

\section{Declarations}

Conflict of interest No conflict of interest has been declared by the authors.

Informed Consent Informed consent was obtained from all individual participants included in the study.

Ethics Approval Ethics committee approval was received for this study from the Akdeniz University Medical Faculty Clinical Research Ethics Committee (Document ID: KAEK-174, Date: 19/02/2020).

\section{References}

Acılar, A., \& Mersin, S. (2015). The relationship between Facebook usage and privacy concerns among university students. Electronic Journal of Social Sciences, 14(54), 103-114.

Alfaya, M. A., Alsamghan, A., Alsaleem, S. A., Alshahrani, M. A., Alfaya, F. A., Alqahtani, Y. S., ... \& Nasser, R. S. (2021). Mobile Phone Addiction and its Relationship to Sleep Quality among the General Population in Abha City, Saudi Arabia. World Family Medicine, 19(3), 82-92. https://doi.org/ 10.5742/MEWFM.2021.94010

Alimoradi, Z., Lin, C. Y., Broström, A., Bülow, P. H., Bajalan, Z., Griffiths, M. D., ... \& Pakpour, A. H. (2019). Internet addiction and sleep problems: A systematic review and meta-analysis. Sleep Medicine Reviews, 47, 51-61. https://doi.org/10.1016/j.smrv.2019.06.004

Alonzo, R., Hussain, J., Stranges, S., \& Anderson, K. K. (2020). Interplay between social media use, sleep quality, and mental health in youth: A systematic review. Sleep Medicine Reviews, 56, 101414. https://doi.org/10.1016/j.smrv.2020.101414

Andreassen, C. S. (2015). Online social network site addiction: A comprehensive review. Current Addiction Reports, 2(2), 175-184. https://doi.org/10.1007/s40429-015-0056-9

Bányai, F., Zsila, Á., Király, O., Maraz, A., Elekes, Z., Griffiths, M. D., ... \& Demetrovics, Z. (2017). Problematic social media use: Results from a large-scale nationally representative adolescent sample. PloS One, 12(1), e0169839. https://doi.org/10.1371/journal.pone.0169839

Baltac1, Ö., Akbulut, Ö. F., \& ve Zafer, R. . (2020). Problematic internet use in the COVID-19 pandemic: A qualitative study. Kırşehir Ahi Evran Üniversitesi Să̆llk Bilimleri Enstitüsü Dergisi, 1(3), $126-140$.

Baltacı, Ö., Akbulut, Ö. F., \& Yılmaz, E. (2021). A current risk factor in problematic internet use: The COVID-19 pandemic. Humanistic Perspective, 3(1), 97-121. https://doi.org/10.47793/hp.872503

Becker, S. P., \& Gregory, A. M. (2020). Editorial Perspective: Perils and promise for child and adolescent sleep and associated psychopathology during the COVID-19 pandemic. Journal of Child Psychology and Psychiatry, 61(7), 757-759. https://doi.org/10.1111/jcpp.13278 
Benke, C., Autenrieth, L. K., Asselmann, E., \& Pané-Farré, C. A. (2020). Lockdown, quarantine measures, and social distancing: Associations with depression, anxiety and distress at the beginning of the COVID-19 pandemic among adults from Germany. Psychiatry Research, 293, 113462. https://doi.org/10.1016/j.psychres.2020.113462

Bilgin, M. (2018). The relationship between social media dependence and psychological disorders in adolescents. The Journal of International Scientific Researches, 3(3), 237-247. https://doi.org/ 10.23834/isrjournal.452045

Çalışır, G. (2015). Social media as a means used in interpersonal communication: a research oriented onto the students of Gümüşhane University Faculty of Communication. Humanities Sciences, 10(3), 115-144. https://doi.org/10.12739/NWSA.2015.10.3.4C0197

Chen, I. H., Pakpour, A. H., Leung, H., Potenza, M. N., Su, J. A., Lin, C. Y., \& Griffiths, M. D. (2020). Comparing generalized and specific problematic smartphone/internet use: Longitudinal relationships between smartphone application-based addiction and social media addiction and psychological distress. Journal of Behavioral Addictions, 9(2), 410-419. https://doi.org/10.1556/ 2006.2020.00023

Chua, S. P., YiRong, B. S., \& Yang, S. Z. (2020). Social media addiction and academic adjustment: The mediating or moderating effect of grit personality. International Journal of Psychology and Educational Studies, 7(3), 143-151.

Coyne, S. M., Rogers, A. A., Zurcher, J. D., Stockdale, L., \& Booth, M. (2020). Does time spent using social media impact mental health? An eight year longitudinal study. Computer Humuman Behaviours, 104, 106-160.

Dalvi-Esfahani, M., Niknafs, A., Alaedini, Z., Ahmadabadi, H. B., Kuss, D. J., \& Ramayah, T. (2021). Social Media Addiction and Empathy: Moderating impact of personality traits among high school students. Telematics and Informatics, 57(2021), 101516. https://doi.org/10.1016/j.tele. 2020.101516

DataReportal. (2021a). Digital 2021: Global Overview Report, (27 January 2021). Retrieved from https://datareportal.com/reports/digital-2021-global-overview-report. Accessed 15 March 2021.

DataReportal. (2021b). Digital 2021: Turkey, (11 February 2021). Retrieved from https://datareportal. com/reports/digital-2021-turkey. Accessed 15 March 2021.

Dong, H., Yang, F., Lu, X., \& Hao, W. (2020). Internet addiction and related psychological factors among children and adolescents in China during the coronavirus disease 2019 (COVID-19) epidemic. Frontiers in Psychiatry, 11, 751. https://doi.org/10.3389/fpsyt.2020.00751

Drahošová, M., \& Balco, P. (2017). The analysis of advantages and disadvantages of use of social media in European Union. Procedia Computer Science, 109, 1005-1009. https://doi.org/10. 1016/j.procs.2017.05.446

Eroğlu, O., \& Yıldırım, Y. (2017). Examining the relationship between the purpose of using social media networks addiction and sleep quality. Turkish Journal of Sports Science, 1(1), 1-10.

Ersöz, B., \& Kahraman, Ü. G. (2020). The changing face of information in the age of informatics: A conceptual study on infobesity. Journal of Applied Sciences of Mehmet Akif Ersoy University, $4(2), 431-444$.

Fernandes, B., Biswas, U. N., Mansukhani, R. T., Casarín, A. V., \& Essau, C. A. (2020). The impact of COVID-19 lockdown on internet use and escapism in adolescents. Revista de Psicología Clínica Con Niños y Adolescentes, 7(3), 59-65. https://doi.org/10.21134/rpcna.2020.mon.2056

Garett, R., Liu, S., \& Young, S. D. (2018). The relationship between social media use and sleep quality among undergraduate students. Information, Communication \& Society, 21(2), 163-173. https://doi.org/10.1080/1369118X.2016.1266374

Ghosh, R., Dubey, M. J., Chatterjee, S., \& Dubey, S. (2020). Impact of COVID-19 on children: special focus on the psychosocial aspect. Minerva Pediatrica, 72(3), 226-235. https://doi.org/10. 23736/S0026-4946.20.05887-9

Gica, Ş. (2020). The effect of social media/smartphone addiction and sleep quality on academic success: A retrospective study in pre-clinic medical faculty students. Selcuk Medical Journal, 36(4), 312-318. https://doi.org/10.30733/std.2020.01471

Goodman, R. (1997). The Strengths and Difficulties Questionnaire: A research note. Journal of Child Psychology and Psychiatry, 38(5), 581-586. https://doi.org/10.1111/j.1469-7610.1997.tb01545.x

Gradisar, M., Wolfson, A. R., Harvey, A. G., Hale, L., Rosenberg, R., \& Czeisler, C. A. (2013). The sleep and technology use of Americans: Findings from the National Sleep Foundation's 2011 Sleep in America poll. Journal of Clinical Sleep Medicine, 9(12), 1291-1299. https://doi.org/10. $5664 /$ jcsm. 3272 
Green Crescent. (2017). Teknolojiye Bağımlı Yaşama! - Lise. Retrieved from https://tbm.org.tr/media/ kitaplar/TBM_lise_teknoloji_icerik_web.pdf. Accessed 21 March 2021.

Griffiths, M. D. (2013). Social Networking Addiction: Emerging themes and issues. Journal of Addiction Research \& Therapy, 4(5), e188. https://doi.org/10.4172/2155-6105.1000e118

Güneş, N. A., Akbıyık, D. İ, Aypak, C., \& Görpelioğlu, S. (2018). Social media dependency and sleep quality in high school students. Turkish Journal of Family Practice, 22(4), 185-192. https://doi.org/ 10.15511/tahd.18.00475

Güvenir, T., Özbek, A., Baykara, B., Arkar, H., Şentürk, B., \& İncekaş, S. (2008). Psychometric properties of the Turkish version of the Strengths and Difficulties Questionnaire (SDQ). Turkish Journal of Child and Adolescent Mental Health, 15, 65-74.

Haand, R., \& Shuwang, Z. (2020). The relationship between social media addiction and depression: A quantitative study among university students in Khost, Afghanistan. International Journal of Adolescence and Youth, 25(1), 780-786. https://doi.org/10.1080/02673843.2020.1741407

Ho, T. T. Q. (2021). Facebook addiction and depression: Loneliness as a moderator and poor sleep quality as a mediator. Telematics and Informatics, 61(2021), 101617. https://doi.org/10.1016/j.tele.2021. 101617

Hou, Y., Xiong, D., Jiang, T., Song, L., \& Wang, Q. (2019). Social media addiction: Its impact, mediation, and intervention. Cyberpsychology: Journal of Psychosocial Research on Cyberspace, 13(1), article 4. https://doi.org/10.5817/CP2019-1-4

İlhan, M., \& Çetin, B. (2014). Comparing the analysis results of the Structural Equation Models (SEM) conducted using LISREL and AMOS. Journal of Measurement and Evaluation in Education and Psychology, 5(2), 26-42. https://doi.org/10.21031/epod.31126

Kashif, M., \& Aziz-Ur-Rehman, M. K. J. (2020). Social media addiction due to coronavirus. International Journal of Medical Science in Clinical Research and Review, 3(04), 331-336.

King, D. L., Delfabbro, P. H., Billieux, J., \& ve Potenza, M. N. . (2020). Problematic online gaming and the COVID-19 pandemic. Journal of Behavioral Addictions, 9(2), 184-186. https://doi.org/10.1556/ 2006.2020.00016

Kline, R. B. (2011). Principles and practice of structural equation modeling. The Guilford Press.

Lee, J. (2020). Mental health effects of school closures during COVID-19. The Lancet Child \& Adolescent Health, 4(5), 397-404. https://doi.org/10.1016/S2352-4642(20)30109-7

Lemenager, T., Neissner, M., Koopmann, A., Reinhard, I., Georgiadou, E., Müller, A., Kiefer, F., \& ve Hillemacher, T. . (2021). COVID-19 lockdown restrictions and online media consumption in Germany. International Journal of Environmental Research and Public Health, 18(1), 14. https://doi. org/10.3390/ijerph18010014

Liu, Z., Tang, H., Jin, Q., Wang, G., Yang, Z., Chen, H., ... \& Owens, J. (2021). Sleep of preschoolers during the coronavirus disease 2019 (COVID-19) outbreak. Journal of Sleep Research, 30(1), e13142. https://doi.org/10.1111/jsr.13142

Meijer, A. M., \& van den Wittenboer, G. L. (2004). The joint contribution of sleep, intelligence and motivation to school performance. Personality and Individual Differences, 37(1), 95-106. https://doi. org/10.1016/j.paid.2003.08.002

Moreno, M. A., \& Uhls, Y. T. (2019). Applying an affordances approach and a developmental lens to approach adolescent social media use. Digital Health, 5, 1-6. https://doi.org/10.1177/2055207619 826678

Muzi, S., Sansò, A., \& Pace, C. S. (2021). What's happened to italian adolescents during the COVID19 pandemic? A preliminary study on symptoms, problematic social media usage, and attachment: Relationships and differences with pre-pandemic peers. Frontiers in Psychiatry, 12, 590-543. https://doi.org/10.3389/fpsyt.2021.590543

Oliviero, B., Emanuela, M., Mattia, D., Elena, F., Karen, S., Grazia, M. M., ... \& Raffaele, F. (2021). Changes in sleep patterns and disturbances in children and adolescents in Italy during the Covid-19 outbreak. Sleep Medicine. https://doi.org/10.1016/j.sleep.2021.02.003

Ophir, Y., Rosenberg, H., Lipshits-Braziler, Y., \& Amichai-Hamburger, Y. (2020). "Digital adolescence": The effects of smartphones and social networking technologies on adolescents' well-being. In Online Peer Engagement in Adolescence (pp. 122-139). Routledge.

Orben, A., Tomova, L., \& Blakemore, S. J. (2020). The effects of social deprivation on adolescent development and mental health. The Lancet Child \& Adolescent Health, 4(8), 634-640. https://doi.org/ $10.1016 / \mathrm{S} 2352-4642(20) 30186-3$ 
Owens, J., \& Adolescent Sleep Working Group. (2014). Insufficient sleep in adolescents and young adults: An update on causes and consequences. Pediatrics, 134(3), e921-e932. https://doi.org/10. 1542/peds.2014-1696

Önder, İ, Masal, E., Demirhan, E., Horzum, M. B., \& Beşoluk, Ş. (2016). Psychometric properties of sleep quality scale and sleep variables questionnaire in Turkish student sample. International Journal of Psychology and Educational Studies, 3(3), 9-21. https://doi.org/10.17220/ijpes.2016.03.002

Özgenel, M., Canpolat, Ö., \& ve Ekşi, H. (2019). Social Media Addiction Scale for adolescents: Validity and reliability study. Addicta: The Turkish Journal on Addictions, 6(3), 629-662. https://doi.org/10. 15805/addicta.2019.6.3.0086

Royal Society for Public Health. (2020). Social media wellbeing tool updated to support the public's mental health during Covid-19. Retrieved from: https://www.rsph.org.uk/about-us/news/socialmedia-wellbeing-tool-updated-to-support-the-public-s-mental-health-during-covid-19.html. Accessed 14 March 2021.

Sampasa-Kanyinga, H., Colman, I., Goldfield, G. S., Janssen, I., Wang, J., Podinic, I., ... \& Chaput, J. P. (2020). Combinations of physical activity, sedentary time, and sleep duration and their associations with depressive symptoms and other mental health problems in children and adolescents: a systematic review. International Journal of Behavioral Nutrition and Physical Activity, 17, 1-16. https:// doi.org/10.1186/s12966-020-00976-X

Savc1, M., \& Aysan, F. (2017). Technological addictions and social connectedness: Predictor effect of internet addiction, social media addiction, digital game addiction and smartphone addiction on social connectedness. Dusunen Adam: The Journal of Psychiatry and Neurological Sciences, 30(3), 202-216. https://doi.org/10.5350/DAJPN2017300304

Scott, H., Biello, S. M., \& Woods, H. C. (2019). Social media use and adolescent sleep patterns: Crosssectional findings from the UK millennium cohort study. BMJ Open, 9(9), e031161. https://doi.org/ 10.1136/bmjopen-2019-031161

Singh, N., \& ve Barmola, K. C. . (2015). Internet Addiction, mental health and academic performance of school students/adolescents. The International Journal of Indian Psychology, 2(3), 98-108. https:// doi.org/10.1016/j.ajp.2020.102290

Singh, S., Dixit, A., \& Joshi, G. (2020). "Is compulsive social media use amid COVID-19 pandemic addictive behavior or coping mechanism? Asian Journal of Psychiatry, 54, 102290. https://doi.org/ 10.1016/j.ajp.2020.102290

Stockdale, L. A., \& Coyne, S. M. (2020). Bored and online: Reasons for using social media, problematic social networking site use, and behavioral outcomes across the transition from adolescence to emerging adulthood. Journal of Adolescence, 79, 173-183. https://doi.org/10.1016/j.adolescence.2020.01.010

Tandon, A., Kaur, P., Dhir, A., \& Mäntymäki, M. (2020). Sleepless due to social media? Investigating problematic sleep due to social media and social media sleep hygiene. Computers in Human Behavior, 113, 106487. https://doi.org/10.1016/j.chb.2020.106487

Twigg, L., Duncan, C., \& Weich, S. (2020). Is social media use associated with children's well-being? Results from the UK Household Longitudinal Study. Journal of Adolescence, 80, 73-83. https://doi. org/10.1016/j.adolescence.2020.02.002

Wang, G., Zhang, Y., Zhao, J., Zhang, J., \& Jiang, F. (2020). Mitigate the effects of home confinement on children during the COVID-19 outbreak. The Lancet, 395(10228), 945-947. https://doi.org/10.1016/ S0140-6736(20)30547-X

Wong, H. Y., Mo, H. Y., Potenza, M. N., Chan, M. N. M., Lau, W. M., Chui, T. K., ... \& Lin, C. Y. (2020). Relationships between severity of internet gaming disorder, severity of problematic social media use, sleep quality and psychological distress. International Journal of Environmental Research and Public Health, 17(6), 1879. https://doi.org/10.3390/ijerph17061879

Woods, H. C., \& Scott, H. (2016). Sleepyteens: Social media use in adolescence is associated with poor sleep quality, anxiety, depression and low self-esteem. Journal of Adolescence, 51, 41-49. https:// doi.org/10.1016/j.adolescence.2016.05.008

Yu, S., Wu, A. M. S., \& Pesigan, I. J. A. (2016). Cognitive and psychosocial health risk factors of social networking addiction. International Journal of Mental Health and Addiction, 14(4), 550-564. https://doi.org/10.1007/s11469-015-9612-8

Publisher's Note Springer Nature remains neutral with regard to jurisdictional claims in published maps and institutional affiliations. 


\section{Authors and Affiliations}

\section{Adem Sümen $^{1}$ D $\cdot$ Derya Evgin ${ }^{2}$}

Derya Evgin

deryaevgin@akdeniz.edu.tr

1 Department of Public Health Nursing, Kumluca Faculty of Health Sciences, Akdeniz University, Antalya, Turkey

2 Department of Pediatric Nursing, Kumluca Faculty of Health Sciences, Akdeniz University, Antalya, Turkey 